\title{
The adoption problem is a matter of fit: tracing the travel of pruning practices from research to farm in Ghana's cocoa sector
}

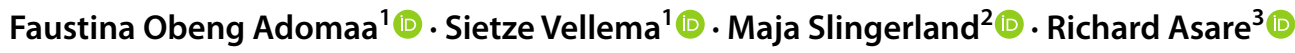

Accepted: 28 December 2021 / Published online: 11 January 2022

(c) The Author(s) 2022

\begin{abstract}
Good Agricultural Practices (GAPs) are central to sustainability standards and certification programmes in the global cocoa chain. Pruning is one of the practices promoted in extension services associated with these sustainability efforts. Yet concerns exist about the low adoption rate of these GAPs by smallholder cocoa farmers in Ghana. A common approach to addressing this challenge is based on creating enabling conditions and offering appropriate incentives. We use the concepts of inscription and affordance to trace the vertically coordinated travel of recommended pruning from research to extension and farming sites, and to describe how pruning is carried out differently at each site. Our analysis suggests that enactments of pruning at the extension site reduce the number of options and space for interactions, and this constrains making the practice meaningful to farmers' repertoires. The conventions guiding and legitimising actions at this site, reinforced by sustainability standards, certification schemes and associated inspections and audits, favour standardised recommendations and consequently narrow room for context-specific diagnostics and adaptions. Therefore, we reframe the adoption problem as a matter of fit between different sites in the 'agricultural research value chain' embedded in the operational cocoa chain. Our contribution problematises the dominant framing of low adoption and highlights that the movement of pruning and the sequential enactment at different sites constrain the affordances available for rendering the practice meaningful to farmers' repertoires. Consequently, addressing the low uptake of GAPs requires institutional work towards conventions that can construct a fit between sites along the agricultural research value chain.
\end{abstract}

Keywords Sustainability standards $\cdot$ Certification $\cdot$ Extension services $\cdot$ Global value chains $\cdot$ Conventions $\cdot$ Fit

Faustina Obeng Adomaa

faustina.obengadomaa@wur.nl

Sietze Vellema

sietze.vellema@wur.nl

Maja Slingerland

maja.slingerland@wur.nl

Richard Asare

R.Asare@cgiar.org

1 Knowledge, Technology and Innovation Group, Wageningen University and Research, Hollandseweg 1, Wageningen 6706 KN, The Netherlands

2 Plant Production Systems Group, Wageningen University and Research, Bornsesteeg 48, Wageningen 6708 PE, The Netherlands

3 International Institute of Tropical Agriculture, CSIR Campus, Augustinho Neto Road, PMB L56 Accra, Ghana

$\begin{array}{ll}\text { Abbreviations } \\ \text { CABI } & \begin{array}{l}\text { Centre for Agriculture and Bioscience } \\ \text { International }\end{array} \\ \text { CHED } & \text { Cocoa Health and Extension Division } \\ \text { CRIG } & \text { Cocoa Research Institute of Ghana } \\ \text { GAP } & \text { Good agricultural practice } \\ \text { GD } & \text { Group discussion } \\ \text { IDI } & \text { In-depth interview } \\ \text { IITA } & \text { International Institute of Tropical Agriculture } \\ \text { STCP } & \text { Sustainable Tree Crop Programme }\end{array}$

\section{Introduction}

Hindrances to the uptake of recommended good agricultural practices (GAPs) have been considered a major challenge to agricultural development in Africa (Meijer et al. 2015; Jha et al. 2020). The emergence of sustainability standards and certification schemes have given this challenge a prominent place in the strategic management of lead sourcing 
and chocolate firms in the cocoa commodity chain. In their responses to public pressures to make cocoa production more sustainable and rising business concerns over secured access to cocoa as raw material, these firms have endeavoured to integrate smallholder farmers into service delivery schemes and associated extension services to increase the uptake and use of sustainable production practices. These corporate strategies reinforce the dominant assumption that training, novel practices and innovative techniques lead the way to sustainable and yield-increasing production practices, and subsequently bring benefits to farmers. Whether this presumed adoption pathway materialises is not self-evident (Alexander et al. 2020). GAP training in the cocoa chain is accompanied by manuals, guidelines and a related set of training and extension activities for fostering adoption, diffusion, and scaling. While research has recorded positive outcomes from such training (Fenger et al. 2017), uptake of promoted GAPs has been recorded as being low (Nmadu et al. 2015). This presents a challenge to the cocoa sector (Dormon et al. 2007). Low levels of uptake and the diffusion of recommended agricultural practices form major strategic concerns for lead firms and their public and civil society partners who are striving to enhance sustainability in the cocoa commodity chain.

GAP training combined with sustainability and certification programmes creates a technology transfer approach that involves notions of adoption, diffusion and scaling (Glover et al. 2019). This perspective frames non-adoption as stemming from unfavourable conditions in the context of adopters. In adoption literature, many studies examine factors within adopting contexts that enable or constrain uptake among farmers (e.g., Meijer et al. 2015; McDonough et al. 2015; Laosutsan et al. 2019). In contrast, we see adoption as a possible emergent outcome of socio-political processes that shape the travel of GAPs (Cook et al. 2021), rather than as a combined result of quality practices and enabling conditions in adopting contexts. GAPs travel from the research sites where they are developed to extension sites where they are transferred and eventually to farming sites, where they are applied.

To understand the likelihood of GAPs having material consequences on the ground and, therefore, contributing to sustainability in the cocoa sector, this paper traces the movement of pruning throughout the "agricultural research value chain" (Alexander et al. 2020) in Ghana as a widely recommended GAP in the operational global cocoa chain. Pruning, as referred to in this paper, broadly refers to a package of guidelines, manuals, artefacts, extension materials, visualisations, or contracts that prescribe recommended practices advanced by the agricultural research value chain. This package is distinct from the set of mundane and gradually evolving practices of farmers cutting unwanted tree parts on their farms. Prescriptions of how to manage trees are built in the package, which therefore affects the selection of pruning techniques and mediates actions.

This turns the travelling package into a pruning script (Akrich 1992; Latour 1992): an evolving framework of action prescribing how cocoa farmers are expected to use tools and techniques in managing their trees and farms. The package is enacted in a set of sequential actions at different sites in the agricultural research value chain that aim to encourage cocoa farmers to adopt recommended pruning practices. The research activities from which the script originated contain different types of pruning, which a variety of mediators at different sites along the agricultural research value chain successively select, translate and inscribe into visuals and manuals that create links between technical content and users (Akrich 1992). Tracing what happens with the pruning script informs the analysis of what recommended pruning practices eventually materialise in the interactions between the extension and farming sites.

The analysis of the adoption trajectory of the pruning script is grounded in science and technology studies, which focuses on the inscription of preferences, principles, categories, and expectations into compact, transportable and persuasive forms, such as graphs and other visualisations (Smith et al. 2000). In line with Latour's analysis of the travel of soil samples (1999), we analyse how the carrying out of the pruning script at different sites creates and selects classifications and options and produces a degree of certainty. We also consider the concept of affordance, linked to the notion of inscription, which is elaborated on in the work of Glover et al. (2017). It is useful to examine how scripts underlying the promotion of pruning mediate relationships between researchers, extensionists and users. Affordances are the potential options for use to which a script lends itself; they outline opportunities for interaction that are built into the scripts and transmit the expectations of promoters to potential users. The affordances are carried out at different sites and reshaped during the movement of technological packages or scripts between sites.

Following Glover et al. (2017) and insights from Latour (1991, 1999), we offer an alternative way of looking at the uptake of GAPs in the cocoa commodity chain, which is attentive to the implications of actions and choices at different levels in the agricultural research value chain for how GAP touches down in the realities of cocoa farmers. Methodologically, we focus on the interface of situated practices, coordination processes and knowledge-based interventions (Vellema et al. 2021). Tracing the travel of a GAP reveals what makes it likely for packages to be flexible enough for a dialogue between different systems of knowledge and practices resulting in contextual adaptation. GAPs are not merely technical packages, but possess cultural and political dimensions; they are constructed and expressed in various institutional forms at different points in the agricultural 
research value chain. To this effect, Glover et al. (2017) highlight that instead of focusing on how packages can be transferred and scaled, a new question emerges: how can the skills and placeless knowledge of scientists be made relevant to, translated into and integrated with forms of knowledge and practices in a way that makes sense on the ground? We engage with this perspective and ask the question: what enables GAPs to be or constrains them from being incorporated into farmers' repertoires?

We advance a conceptualisation of the travel of pruning based on inscription and affordance with an institutional perspective on how this unfolds in a vertically coordinated process. The travel of GAPs is influenced by governance mechanisms in the cocoa value chain that promote standardisation and uniformity. We add this perspective so that we are able to assess the ways and extent to which cocoa farmers can accommodate, appreciate, resist, subvert or bypass the inscriptions and modes of action included in efforts to transfer and promote recommended pruning practices. It is not self-evident that the mobility of pruning is a two-way process, even though the expectations of pruning at the research and farming sites are not that far apart. Therefore, we provide an institutional perspective on the notions of inscription and affordance to understand the persistence of low uptake of GAP.

The institutional perspective uses the concepts of fit and convention. 'Fit' originates from organisation and management studies (Nadler and Tushman 1980; Ansari et al. 2010); it is used to examine how characteristics of GAPs that arrive in the farming site, either fit with farmer's repertoires or do not. To comprehend the observed (mis)fits, we engage with the notion of convention (Diaz-Bone 2016; Ponte 2016), from governance studies literature, to examine the enabling or constraining institutional conditions at play in the agricultural research value chain, embedded in global commodity chains. While our analysis engages with GAPs at the distinct sites, our study neither evaluates the knowledge of GAPs at the sites nor advances arguments on the dichotomy between scientific and farmers' situated knowledge. Instead, we shift attention to and provide an institutional lens for examining the vertically coordinated travel of GAP tangled with sustainability and certification programmes in the cocoa chain and identify enablers or constraints to making GAPs relevant and fit with farmers' repertoires.

The paper is organised as follows. After this introductory section, we present the theoretical perspectives from which we derive the main elements of our analytical framework. Next, we introduce the methods for tracing the travel of pruning as a recommended practice in Ghana. The results section traces the travel of pruning from research to extension and farming sites and unravels decision-making and coordination processes at and between multiple levels in the knowledge chain; this informs our institutional understanding of the vertically coordinated travel of pruning. We end with a discussion on the conditions that enable or constrain fitting and contribute to observed fits and misfits, and we conclude with recommendations.

\section{Analytical framework}

Technology transfer thinking dominates the adoption literature and is often accompanied by notions of diffusion and scaling. These notions ascribe neutrality and universal applicability to scientific knowledge (Glover et al. 2019). Pruning for instance, is considered as a neutral package of knowledge on what, how and when to prune, what equipment to use and for what outcome. Its movement into farming is then conceived as transferring knowledge and recommendations through trainings. Glover et al.'s (2017) perspective on the uptake of technological packages, however, highlights that technological packages go through processes of standardisation and simplification to make them mobile and enable them to travel from research stations to farmers' fields, and these have implications for the applicability of the packages.

Glover et al. (2017) highlight two processes as being crucial for what happens to technological packages and how they can be used: inscription and affordance. Inscription concerns the work done by designers to build expectations into standard packages of how they are to be used to achieve their intended outcomes. Latour (1991) shows that users can adopt, subvert, change, resist or ignore scripts. For our analysis, we detail how practices and interactions of researchers and extensionists convert expectations of what pruning can do into signs, such as visuals or pictures, and words, such as manuals or training materials. We document the production and transmission of information as forms of inscription happening during the travel of the pruning script.

The affordance of packages concerns the potential options for use and opportunities for interactions with the packages. Affordance depends on the characteristics of the packages that enable or constrain the ways they can be employed, as well as the flexibility of interpreting them. According to Glover et al. (2017), the uptake of technological packages depends on the conditions for unpacking their affordances into the repertoires of users. Examining processes and levels of inscription of technological packages, and their affordances and site-specific enactments is, therefore, essential to understanding the uptake of such packages.

Following from Glover et al. (2017), we document the production and transmission of information as forms of inscription happening during the travel of a pruning script. In the setting of the agriculture research value chain, inscriptions are carried out at different sites, which refashions the affordances at the subsequent site. The concept of affordance-linked to the notion of inscription in the work of 
Glover et al.-is therefore useful to closely examine how scripts underlying the promotion of pruning mediate relationships between researchers, extension officers and users (Fig. 1). We trace the travel of recommended GAPs from the site of research to extension and to farming and examine their distinct site-specific enactments. We conceptualise GAPs as site-specific configurations carried out through practice and situated within specific institutional mechanisms.

In the cocoa chain, GAPs are tangled with standards and certifications, and have interdependences at various levels of the commodity chain. They are embedded in governance mechanisms in the vertically coordinated chain. The intrinsic dynamics of specific sites mediate what practices actors consider legitimate and whether and through what processes they are adopted (Bromley et al. 2012). Consequently, technologies used within specific contexts pick up other characteristics beyond their technical characteristics. The sites where technologies originate and transfer, for instance, shape their characteristics and how they interact with users (Glover et al. 2017). Like diffusing practices in organisational settings, technologies are socially meaningful, multifaceted bundles of knowledge rather than neutral innovations (Ansari et al. 2010, p. 82). GAPs such as pruning entail more than technical artefacts; they imply a variety of rules and norms emerging from site-specific actions. These site-specific institutional features direct the travel of GAPs and affect degrees of institutional coordination and alignment (Cook et al. 2021) between the different levels of the agricultural research value chain.

Unpacking package affordances and incorporating them into farmers repertoires requires a fit between packages' characteristics and users' practices. Nadler and Tushman (1980, p. 45) define fit as "the degree to which the needs, demands, goals, objectives, and/or structures of one component are consistent with those of another component". Uda et al. (2018) highlight that fit is a two-sided concept that focuses on tensions and synergies resulting from what works (or not) as practices move from one domain to another. While examining how practices diffuse in organisational settings, Ansari et al. (2010) use the concept to examine compatibilities between characteristics of a practice in two domains of an organisation and how (mis)fit triggers different patterns of adaptation. They distinguish between technical, cultural and political characteristics of diffusing practice to analyse fit between sites. They conceptualise technical fit as the degree to which characteristics of a practice are compatible with technologies already in use by potential adopters. Cultural fit is the degree to which the characteristics of a practice are compatible with the cultural values, beliefs, and decision-making practices of potential adopters. Political fit is the degree to which the implicit or explicit normative characteristics of a practice are compatible with the interests and agendas of potential adopters. We adopt Ansari et al.'s (2010) technical, cultural and political characteristics of fit and heed Cox's (2012) call to define characteristics of the practice for which we analyse fit.

Therefore, we unpack pruning practices at the distinct sites into technical, cultural and political characteristics and discuss compatibilities within these characteristics. We use compatibilities and incompatibilities in the characteristics to reveal fits and misfits around pruning practices, and frame adoption and non-adoption as arising from (mis)fits in the characteristics of the arriving package and realities in the farming site. Fit is not a static concept but reflects a dynamic process (Schouten et al. 2016), so we analyse the emergence of fitting and misfitting within the unfolding practices of using manuals and delivering extension services that constitute interfaces where the research, extension and farming sites interact (Fig. 1)

We deepen our understanding of observed fit and misfit through the lens of convention theory to unearth conditions that either enable or constrain unpacking the affordances of pruning. Diaz-Bone (2016, p. 215) defines conventions as
Fig. 1 Analytical framework for the study




"socio-cultural frames for mobilizing a shared interpretation of objects, actions, goals, and collective intentions involved in situations of production, distribution, and consumption". Conventions serve as a guide for action and collective systems to legitimise those actions and include processual and situational factors that shape specific institutional trajectories (Ponte 2016). Convention theory shifts attention to the institutionally situated characterisation of individual and collective actions, particularly the values, visions and norms that guide processes of coordination (Wilkinson 1997). Realigning a practice to be compatible with a norm, manifest in prescribed GAPs in certification schemes, has become a major coordinating process in commodity chains (Ponte 2016; Ponte and Gibbon 2005). We use convention theory to unearth shared norms, values and interpretations (Geurts 2018) that enable or constrain the unpacking of pruning affordances and their incorporation into farmers' repertoires (Fig. 1). Figure 1 represents the analytical framework underpinning our results and discussions.

\section{Methods}

\section{Context}

Practitioners in the field of tree crops highlight pruning as an important low-cost choice for increasing productivity, as trees' energy is channelled into fruit production (Vos et al. 2003). Removing unwanted plant parts through pruning is considered an essential management practice in tree crops such as apple (Elfving 1990), macadamia (Huett 2004) and cocoa (Govindaraj and Jancirani 2017). In cocoa, pruning is expected to improve light capture and efficient nutrient use (Opoku-Ameyaw et al. 2010; Asare et al. 2018) and to find a balance between growth and yield (Govindaraj and Jancirani
2017). Pruning is also recommended for controlling pests and diseases and reducing pesticide use (Opoku-Ameyaw et al. 2010), as concerns over the environmental hazards of pesticides used on cocoa have heightened (Denkyira et al. 2016; Okoffo et al. 2016). Policy makers, standard organisations and private firms in the cocoa sector also promote pruning through sustainability-certification programmes.

In Ghana, the Cocoa Research Institute of Ghana (CRIG) and institutions, such as the International Institute of Tropical Agriculture (IITA), conduct research on GAPs, generate knowledge and translate this knowledge into manuals used in extension services. Extension service providers include the public Cocoa Health and Extension Division (CHED) and the extension units of private sourcing and chocolate companies collaborating with civil society organisations. Extension is instrumental to link this translated knowledge to many cocoa farmers. The adoption of pruning in the West African cocoa sector, however, is noted to be low (Govindaraj and Jancirani 2017), and Ghana is no exception (Dormon et al. 2007). In this setting, we used the methods stipulated below to document the travel of pruning through the layered setup of knowledge transfer from the research to extension and farming sites in Ghana.

\section{Data collection}

We collected data on pruning practices in the three sites (Table 1). CRIG and IITA formed the research site. Field work took place through ongoing extension activities on pruning in farming communities in three districts: Amenfi West in Western region, Bibiani-Anhwiaso-Bekwai in Western North region and Atwima Mponua in Ashanti region.

Additionally, we observed 13 pruning activities in the 2018/19 cocoa season. These included one mass training session, two demonstration-farm visits, four coaching and

Table 1 Data collection methods and participants in research

\begin{tabular}{|c|c|c|c|}
\hline Site & Data collection method & Participants & Data collected \\
\hline \multirow[t]{2}{*}{ Research } & In-depth interviews (IDI) & IDI with three agronomists & $\begin{array}{l}\text { Knowledge and practices of pruning, interactions } \\
\text { with extension officers/farmers, challenges and } \\
\text { solutions }\end{array}$ \\
\hline & Document Analysis & Analysis of five manuals (Details in Table 2) & $\begin{array}{l}\text { Benefits of pruning stated, type }(\mathrm{s}) \text { of pruning } \\
\text { addressed, art of pruning described }\end{array}$ \\
\hline \multirow[t]{3}{*}{ Extension } & IDIs & $\begin{array}{l}\text { IDI with six extension officers, one field trainer } \\
\text { and seven trained pruners }\end{array}$ & $\begin{array}{l}\text { Knowledge and practices of pruning, extension } \\
\text { delivery and evolution }\end{array}$ \\
\hline & Group discussions (GD) & One GD with 16 extension officers & $\begin{array}{l}\text { Interactions with agronomists, farmers and auditors, } \\
\text { challenges and solutions }\end{array}$ \\
\hline & Document Analysis & $\begin{array}{l}\text { Six teaching and learning aids, one pruning service } \\
\text { contract, one certification contract, one certifica- } \\
\text { tion standard guideline }\end{array}$ & $\begin{array}{l}\text { Benefits of pruning stated, type }(\mathrm{s}) \text { of pruning } \\
\text { addressed, art of pruning described }\end{array}$ \\
\hline \multirow[t]{2}{*}{ Farming } & IDIs & 12 IDIs with farmers & \multirow{2}{*}{$\begin{array}{l}\text { Knowledge and practices of pruning, interactions } \\
\text { with extension officials, challenges and solutions }\end{array}$} \\
\hline & GDs & Four GDs (8-12 farmers per group) & \\
\hline
\end{tabular}


six direct pruning of trees for farmers called 'gang pruning'. In the coaching and gang pruning, we conducted followup discussions to clarify some of the observed interactions. Some interviews, group discussions and observations were recorded, and the audio and video recordings were transcribed to capture vital details. For the unrecorded ones, detailed notes were taken during data collection.

\section{Data analysis}

We combined data from the multiple sources and methods in our analysis. We compiled the notes and transcripts into summaries for the distinct sites, then analysed the summaries. We focused on the content of the summaries to examine site-specific enactments of pruning (Coffey and Atkinson 1996). We compiled the emerging insights into cross cutting thematic codes. These thematic codes were: definition of pruning, source of pruning definition, types of pruning typified, weight given to types of pruning, description of the art of pruning, factors to consider when pruning, effects of pruning highlighted, weight given to effects, and labelling of farmers and researchers'/extension officers' way of pruning. These crosscutting themes allowed for examination into how pruning was carried out at each site. We also focused on the interactional contexts and dynamics in the sites to examine interactions among the sites and how pruning travels from one site to the other (Elliot 2005). The analysis of site-specific enactments and the travel of the practice were not sequential; they were cyclical and allowed for in-depth understanding of the dynamic process of how pruning is constructed in each site and the interactional dynamics among the sites (Kumar 2014). We present this in our results section.

We then examined the crosscutting themes using our theoretical lenses (see Fig. 1). We typified the engendered characteristics of pruning in each site into technical, cultural and political dimensions, and examined the compatibilities in the characteristics among the sites using the concept of fit. We paid attention to conditions that enable or constrain compatibilities among pruning practices in the distinct sites. Subsequently, we used convention theory to unearth the conventions that shape how pruning is carried out in each site and how and in what form the practice moves from one site to the other.

\section{Results: the vertically coordinated travel of pruning}

In this section, we trace the travel of pruning from the research site, through manuals to the extension site and through extension delivery activities to the farming site. We focus on site-specific enactments, levels of inscription and the unpacking of affordances of the practice as it travels.

\section{Pruning at the research site}

At the research site, researchers and agronomists showed that diverse types of pruning exist for different purposes. Formation pruning is conducted on young cocoa trees to adjust the height of the first jorquette and to create desirable shape during establishment; structural pruning is done to shape the canopy of matured cocoa trees to a desired size and architecture; sanitation pruning involves the removal of diseased and unnecessary branches, chupons, epiphytes, mistletoes and mummified pods (Opoku-Ameyaw et al. 2010; David 2011). The agronomists we interviewed highlighted that pruning improves aeration, reduces pests and diseases, and improves light capture and efficient nutrient use, all of which enhances productivity. However, while formation and structural pruning primarily give good tree shape, sanitation pruning improves tree health and reduces pests and diseases.

Govindaraj and Jancirani (2017) highlighted that pruning's effect on productivity depends on how much biomass one removes from the tree during pruning, among other factors; they distinguished between deep/heavy (30\%), medium (20\%) and light (10\%) pruning. Asare et al. (2018) assert that removing more than $25 \%$ of tree canopy can potentially starve the tree and be detrimental to its growth. Govindaraj and Jancirani (2017) considered medium pruning as having the greatest effect on pod attributes. Agronomists indicated that the main branches of cocoa trees carry pods. Accordingly, one needs to carefully consider if and what main branches should be cut to avoid negative effects on pod-bearing.

The agronomists further indicated that farm-specific conditions determine tree response to pruning. These conditions include the presence or absence of shade trees, soil fertility status and microclimate. They specified that cocoa trees live and interact with other shade trees. Thus, light capture for productivity enhancement, for instance, depends on the mutual shading of cocoa trees and that of other shade trees (Govindaraj and Jancirani 2017). For pest and disease reduction, while pruning's effect on improving sunlight penetration can prevent black pod disease (Opoku-Ameyaw et al. 2010), it can increase capsids that thrive in sunlight (Dohmen et al. 2018). Additionally, intensified rainfall, temperature changes and prolonged dry seasons influence trees' response to pruning (Dohmen et al. 2018). The agronomists, therefore, concluded that pruning is a context-specific practice and must be situated in farm-specific conditions.

Agronomists mentioned that due to contextual specificities of pruning, one needs expertise in giving pruning recommendations to farmers. One agronomist opined that "both 
good and bad pruning can provide adequate sunlight in the farm", but the "consequences of bad pruning is detrimental", so having an "eye for pruning" is vital (Agronomist, Tafo, 9/9/19). They noted that expertise is particularly necessary for avoiding the dire consequences of pruning on tree health and productivity.

At the research site, pruning is used as a practice that consists of diverse methods and is used for diverse purposes and context-specific outcomes. The affordances of pruning as contained in this site acknowledge diversity in pruning types and different techniques for pruning. Its outcomes are also diverse, including increased productivity, balanced tree growth and yield, enhanced tree health and reduced incidence of pests and diseases. It also allows for a diagnostic capacity to access farm-specific conditions to situate the practice. The site constructs pruning as an open-ended script that allows extension workers and farmers to rewrite and localise it.

\section{The travel of pruning to extension site through manuals}

Manuals represent an interface of interaction between the research and extension sites. They embody abstract representations of reality constructed into words and illustrations through inscriptions for reference (Latour 1999). Through manuals, researchers are able to standardise information on pruning and enable it to travel to the extension site where officers can interpret and use it. Manuals constitute a level of inscription with potential implications on the affordances of pruning.

Manuals on cocoa cultivation in Ghana (Table 2) have had information on pruning since the 1980s and have typified diverse pruning types for diverse purposes since 2003. In illustrating pruning, however, information in the manuals concentrate on tree shape. The CABI and STCP manuals, for instance, focus on heavy/structural pruning in an eightstage illustration sourced from the ACDI/VOCA SUCCESS project in Indonesia. The manuals present an unpruned tree as stage one, consider sanitation pruning as stage two and dedicate stages three to eight to pruning that results in a fourmeter tall tree with three to four main branches and a funnelshape canopy. The CRIG 2010 and CocoaSoils manuals on the other hand, portrayed the processes of conducting the diverse types of pruning. However, they also illustrate treeshape before and after pruning, reflecting an emphasis on tree-shape in illustrations.

The manuals highlighted diverse benefits of pruning (Table 2). However, they gave credence to the outcomes of structural pruning. For instance, they state that "the best cocoa tree has one stem only and two or three main branches, with enough side branches and leaves to capture more sunlight" (STCP Manual 2011, p. 7; CocoaSoils
Manual 2021, p. 27). The CABI and STCP manuals state that the productivity of trees pruned as illustrated is higher and underscore the importance of keeping such structure through maintenance pruning. The CRIG 2010 manual also notes that pruning provides shape to the plant and improves aeration and reduces incidence and spread of pests and diseases: these factors are essential for increasing productivity. The manuals accentuate the significance of structural pruning for improving productivity and tree health.

The manuals provide little to no attention to farm-specific contextual factors to consider when pruning. The information is focused on the cocoa tree and gives standard recommendations about which unwanted branches and materials should be pruned, when to prune and what equipment to use. The agronomists said that to counter the trade-off from standardisation, the ideal practice is for agronomists to train extension workers on the specificities and situatedness of pruning. However, they also said that such training rarely takes place; if it does, the information from the manuals is reproduced.

Although the inscription of pruning in manuals acknowledges diverse types of pruning, illustrations emphasise structural pruning and give credence to its outcome. The specificities and situatedness of pruning also filter into standard recommendations. Thus, the affordance of pruning as consisting of diverse types for diverse purposes narrows. Its construction as an open-ended script that allows for localisation and associated diagnostic capacities for context-specific adaptation also fades.

\section{Pruning at the site of extension services}

At the extension site, extension officers specified the existence of formation, structural and sanitation pruning for diverse purposes including increased productivity, improved tree health and reduced pests and diseases. However, officers often described pruning with phrases such as desired tree-shape, 3-4 branches and funnel-shaped canopy. They used manuals as sourcebooks and their teaching and learning aids had illustrations of pruning provided in the manuals. The officers indicated that they gave pruning recommendations to farmers on what branches to cut, how to cut them, what time of the year to cut and what equipment to use as indicated in manuals or received in their training. However, few extension officers said that in addition to these standard recommendations, they considered local weather and soil conditions. These officers indicated that they gained this contextual insight from years of working with farmers and learning from their experiences. For the other officers with less experience, they relied on the manuals to provide them with pruning recommendations. These officers equated recommended pruning with illustrations in manuals. 


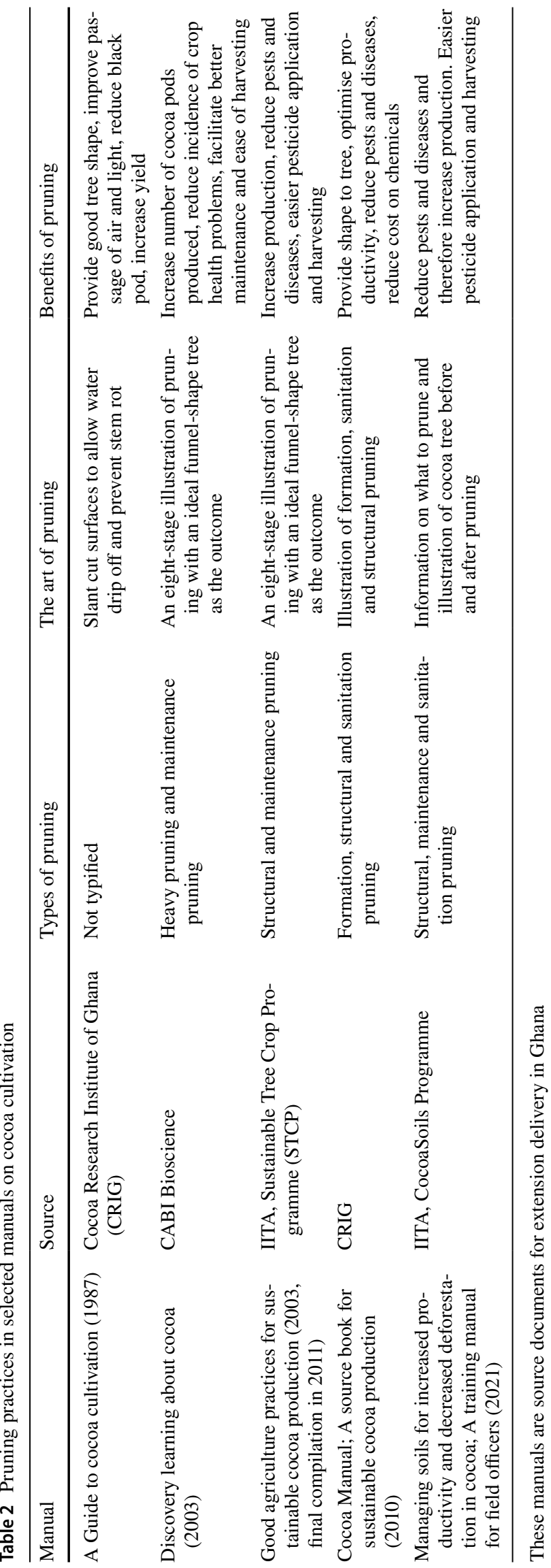


The officers indicated that pruning is a key part of sustainability and certification schemes and Ghana Cocoa Board's ongoing productivity enhancement programme. Certification schemes, for instance, specify pruning as mandatory practice. The checklist of one certification programme we examined showed that pruning is to be regularly conducted to obtain optimal tree structure and health. Officers trained farmers on recommended pruning as illustrated and, in some instances, trained other people to directly prune trees for farmers. A contract signed between one firm and farmers for direct pruning service showed that the farmers were appointing the company to structurally prune their farm, and this was a principal clause for defining breach of contract. Extension officers emphasised the importance of farmers adhering to recommended practice for their farms to pass certification audits and inspections.

At the site of extension, information in manuals is being reproduced in teaching and learning aids and is being translated into activities geared towards training farmers on recommended pruning as a key component of sustainability efforts. Pruning is treated as an inflexible and fixed recommendation. Its affordances reduce with regards to diversity and specificity, situatedness, contextual adaptability and context-specific diagnostic capacity. The practice becomes more selective and standardised, and dovetails with standard and certification schemes with related checklists and audits.

\section{The travel of pruning to the farming site through extension delivery}

Extension delivery is an interface of interaction between the extension and farming sites. Extension officers give information on pruning during extension activities and farmers interpret and use this information. Extension activities constitute a second level of inscription with potential implications for the affordances of pruning.

Varied extension delivery activities on pruning exist in Ghana (Table 3). These activities have fostered diverse interactions between extension officers and farmers. In the mass training we observed, the extension officer asked farmers what they knew about pruning at the beginning of the training. He then told farmers what pruning is, its importance and showed farmers how to prune on their farms. In the demonstration sessions, officers usually told farmers what the recommended practice is and started demonstrating it to farmers. At every stage of demonstration, officers explained why they cut a branch and invited some farmers to demonstrate what they had seen. Farmers asked officers to clarify further when what officers said or demonstrated deviated from what farmers knew or did. For instance, this included when officers cut branches having cherrelle and farmers thought that this would decrease yield, and when an officer said that pruning could increase yield by about $30 \%$ and farmers were sceptical about yield increase from pruning without fertiliser application.

Officers said that farmers had attended many training sessions and yet often did not adopt recommended pruning on their farms. One officer's statement that "farmers find it difficult to understand what we say in trainings; they need to see us demonstrate it" (Private extension officer, Nyinahin, 21/5/19) suggested a need for demonstration sessions. However, they also noted that farmers were not convinced with what they had seen in demonstration farms. "They [farmers] think the effect of pruning cannot be just a result of pruning" (Public extension agent, Adjoufua, 1/11/18), “... they [farmers] think we do some extraordinary treatments to the farm" (Private extension agent, Asankragua, 6/4/19). Officers specified that the ideal situation was for farmers to receive recommended pruning on their individual farms.

Coaching and gang pruning occurred on farmers' farms (Table 3). In these activities, some farmers showed active resistance to recommended pruning due to perceived detrimental effects to cocoa trees. Farmers and officers spent a considerable amount of time discussing their distinct positions on what, how and why to prune. Officers explained their position using their knowledge on recommended pruning while farmers gave contextual information on their farms to explain their position. In some instances, they reached consensus. For instance, when farmers appreciated coaches' or pruners' reasons for what and how to prune, or when coaches or pruners were also farmers and appreciated the farm owners' basis for wanting the trees pruned differently.

Table 3 Extension activities on pruning in Ghana

\begin{tabular}{|c|c|c|}
\hline Delivery method & Rationale & Setting and activity \\
\hline Mass training & Farmers need to learn about pruning & $\begin{array}{l}\text { Classroom setting. Extension officers train farmers on pruning } \\
\text { with teaching and learning aids }\end{array}$ \\
\hline Demonstration & $\begin{array}{l}\text { Farmers learn better by seeing. They need to see the art of } \\
\text { pruning being demonstrated in a farm }\end{array}$ & $\begin{array}{l}\text { Demonstration farm. Extension officers demonstrate the art of } \\
\text { pruning to groups of farmers }\end{array}$ \\
\hline Coaching & $\begin{array}{l}\text { Farmers have unique learning abilities. They need segmented } \\
\text { and tailor-made coaching }\end{array}$ & $\begin{array}{l}\text { Farmer's farms. Field trainers coach farmers in smaller groups } \\
\text { or individually during pruning }\end{array}$ \\
\hline Gang pruning & $\begin{array}{l}\text { Farmers do not have the labour ability and skills to prune or } \\
\text { do not want to prune. They need direct pruning services }\end{array}$ & $\begin{array}{l}\text { Farmers' farms. Trained pruners directly prune trees for farm- } \\
\text { ers }\end{array}$ \\
\hline
\end{tabular}


In some instances, there was no consensus. Officers, however, cajoled farmers into accepting recommended pruning to enjoy the full packages of intervention, which included spraying and hand pollination. In other instances, farmers grudgingly accepted recommended pruning so they were able to pass certification inspections. In a gang pruning activity, for instance, one farmer said "I am only accepting this [officers recommended branches to cut], because you said my farm will not pass certification if I do not cut these branches" (Observation 5, Manse, 14/5/19). Officers highlighted that they had to ensure that farmers pruned as recommended to be able to meet internal control measures and subsequently pass certification audits.

In other instances, farmers refused to allow trained pruners to prune as recommended. Farmers indicated that it was risky to allow pruners who do not understand how cocoa trees behave to prune branches that would reduce yield or kill the tree. Pruners, on the other hand, said farmers were obstructing their work, and failure to prune as recommended implied that they did not prune well and could not justify their actions to internal control officers who would inspect the farm afterwards. To these pruners "it is better to label farms as not pruned than not well-pruned" (Trained pruner, Amoamang, 12/3/19). Officers expressed displeasure about farmers' non-adherence to recommended pruning. They thought that "farmers should be able to sacrifice and prune their farms" to reap the benefits (Private extension officer, Accra, 14/8/18).

The extension delivery methods had different underlying rationales and settings (Table 3 ), so fostered different interactions. However, the delivery approach focused on transferring recommended pruning to the farming site. This second level of inscription through extension activities dovetails into certification schemes and interventions that involve inspections and audits. This reinforced inscription in manuals that are carried out in the extension site consisting of reduced affordances in terms of diversity and specificities, situatedness, contextual adaption and context-specific diagnostic capacities. Pruning was promoted as an inflexible package with standard recommendations.

\section{Pruning at site of farming}

On the farming site, farmers indicated that cutting unwanted branches has been part of their management practices for decades. They said: "we cut the downward looking branches so that it will be easy to walk through the farm" (Interview 3, Amoamang, 12/3/19), "my farm became too dark [shady] and wet [damp] so I cut some of the branches" (Interview 6, Benchema, 8/4/20) "I cut the dead branches so that insects cannot hide in them" (Interview 11, Nyinahin, 20/4/20). According to farmers, they did this to improve sunlight penetration and prevent dampness and its influence on pests and diseases. The farmers however, described the cut branches as slim, weak, tiny, downward looking, diseased or dead.

Farmers indicated that although cutting unwanted branches is an old practice, they did not refer to it as pruning. For these farmers, the use of the term 'pruning' by extension officers and its promotion as a recommended practice referred to the type of pruning that centred on shaping the structure of the tree. Farmers indicated that cutting 'big branches' and opening up the canopy 'too much' could lead to dire consequences. Some farmers recounted yield reduction resulting from cutting main branches. They cited factors such as the rains did not come early, the sun was too much, and I did not apply fertiliser to identify stresses in tree response to pruning they experienced. While some farmers had experienced these adverse effects themselves, others had learned from the experiences of other farmers. They highlighted the importance of learning from the mistakes as much as the successes of other farmers concerning pruning.

The farmers highlighted the potential of extension officers' way of pruning on nutrient maximisation and its positive effect on productivity. They explained this using a bowl of food scenario they had learned during training. They said that a bowl of food (nutrients) could feed less people (tree branches) to work more satisfactorily (more productively) than more people. While they acknowledged this, they showed that farms are not the same, and even in the same farm, different soil conditions exist. One farmer narrated:

It is important to consider the type of land on which the cocoa is planted so that the trees do not die after pruning. Some trees look like they are dying during the dry season, and it is dangerous to prune them. There is a farm on the road to my farm, the land is hard and cracks during the dry season. They [trained pruners] pruned that farm last year and the cocoa trees have been struggling since then. Anytime I pass by, I tell myself that this woman should not have allowed these pruners to destroy her farm (GD 4, Domeabra 15/3/19).

According to the farmers, deciding what to cut and how to cut unwanted branches involves considering soil fertility levels and the ability to apply fertilisers or not, the slope of the land and depth of top soil, rainfall and temperature variability, the presence of shade trees on the farm and the position of such trees in relation to cocoa trees. To these farmers, the composite task of managing and maintaining trees involves assessing sunshine and humidity in the specific location as well as age and status of the tree before deciding what and how to cut unwanted parts. It involves diagnosing the status of the tree situated in the farm and selecting appropriate recipes for ensuring yield. At the site of farming, pruning is carried out as a situational practice that one learns by doing and with context-specific factors to consider. 


\section{The travel of a GAP and its effects}

The above traces the vertically coordinated travel of recommended pruning through the agricultural research value chain embedded in the operational cocoa chain. Tracing the travel indicates that the affordances of pruning reduced as it moved from research to extension to farming site. The rich but placeless knowledge of scientists recognised a variety of pruning practices that could be used under different circumstances and for multiple purposes. However, inscription in manuals, a necessary step for making the GAP mobile, entailed setting a standard for pruning and increasingly gave weight to a single pruning technique. This move towards standardisation and a strong focus on promoting structural pruning materialised in the step translating pruning into recommendations and guidelines used and unpacked in the extension site and was reinforced by the anchoring of extension delivery in certification programmes.

The result of making pruning mobile is that the practice of pruning that arrives in the farming site is restricted and the multiplicity of options for use tailored to diverse conditions visible at the research site evaporated along the way. Refining and standardising the placeless knowledge of scientists and researchers on GAPs to travel to the sites of extension and farming requires levels of inscription. Much like Latour's (1999) work on the travel of soil samples, pruning, which is a context-specific art, becomes movable through inscription processes in the manuals that standardised it. These inscription processes amplify the standardisation and relative universality of the art; however, they reduce their locality, particularities, materiality and multiplicity (Latour 1999, p. 71). While these inscriptions are necessary to make the package mobile, they influence the content and affordances of the package and limit potential options for use (Glover et al. 2017). This unintended consequence of making GAPs mobile has implications for connecting pruning as a GAP to farmers' repertoires.

\section{Discussion}

The analysis of the travel of pruning, as a recommended GAP, opens conceptual space for reframing the adoption problem as a matter of fit and, subsequently, for using the notion of conventions to identify conditions that add to the persistence of low adoption. The low uptake of GAPs observed in the cocoa sector is widely framed as an adoption challenge stemming from constraining conditions in adopting contexts (e.g., Dormon et al. 2007). This framing of the problem drives efforts to increase training and use groups to offer direct pruning services to increase uptake of what is considered a neutral package of scientific knowledge. This paper reframes the problem as a matter of fit between sites through which GAP travels and advances a conceptualisation of the travel of pruning based on inscription and affordance with an institutional perspective on how this unfolds in a vertically coordinated process. This section exposes the characteristics of pruning brought about through distinct site-specific enactments and identifies (mis)fits between the vertically connected sites.

Unpacking the affordances of pruning in each site engenders specific technical, cultural and political characteristics (Table 4). In terms of technical characteristics, the practice of pruning at the research site consists of diverse types, has diverse outcomes and needs context-specific diagnosis. The research site encodes the variety of pruning practices in manuals. At the site of extension, however, pruning is carried out as a standardised practice with generic diagnosis focused on the structure of the cocoa tree. The extension site puts little emphasis on translating situated diagnoses into context-specific recommendations. The standard practice of pruning as carried out in the extension site arrives at the farming site where pruning is carried out as a situated practice with diverse outcomes and needing contextspecific diagnosis. Pruning entering farmers' realities as a GAP reveals a misfit with the technical characteristics of the repertoire of pruning practices already in use in the farming site.

The cultural characteristics relate to how decisions are made, and options are selected in each site. The research site values and normalises diversity in pruning types and constructs pruning as an open-ended script for localisation. The extension site, however, values and normalises structural pruning and constructs pruning as a standardised practice with fixed recommendations that are transferable to farmers in the form of training and guidelines. The manuals and training offer little guidance in how to define and evaluate the purposes of different 'good pruning practices' and assess their appropriateness for specific circumstances. This standardised recommendation of pruning relates to auditing and certification, which basically check compliance with a limited set of prescribed guidelines. The affordances of the practice that eventually touch down at the farming site have been altered through the enactment in the extension site. This contrasts with the observations of decision-making processes at the farming site, which value and normalise diverse pruning techniques and construct pruning as a flexible practice that one learns by doing.

The political characteristics of the practice relate to what is prioritised and what effects of the practice are valued. The research, extension and farming sites all value pruning's plausible positive effects on reduced pests and diseases. Regarding pruning's effect on productivity, however, the research site prioritises productivity pre- and post-pruning, while the extension site enacts improved productivity as a post-pruning outcome. The farming site normatively 


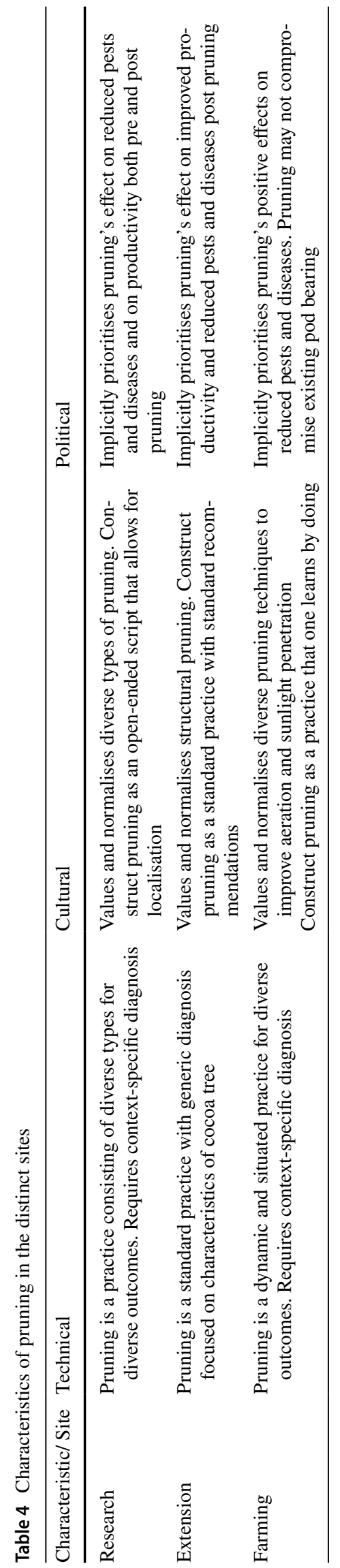

prioritises pruning's non-disruption of existing productivity. Epitomising the relationship between loss aversion and decision making among farmers (Jin et al. 2020), they select pruning techniques based on evaluations of contextspecific practices and are geared towards non-compromised pod-bearing. When farmers select structural pruning - the generic recipe prevalent in extension services-it depends on what is prioritised at specific moments in time and in accordance with farm-specific conditions. This experimental and evaluative mode of priority setting in the farming site, which allows farmers to find a balance for productivity preand post-pruning, diverges from the fixed priorities emerging in the extension site.

Our analysis suggests that enactments of the pruning script in the middle of the knowledge chain may reduce the number of options and spaces for interactions, which reinforces the low uptake of GAPs. Remarkably, the characteristics of pruning at the research and farming site may be commensurable. The research and farming site share the notion that pruning is a specific art, and using it effectively requires adapting the practice to specific farm and agro-ecological conditions (Govindaraj and Jancirani 2017; Dohmen et al. 2018). However, the unpacking of the pruning script during its transmission in the form of manuals and extension services creates contradictions and misfit. Consequently, the paper problematises the dominant narrative, which frames the issue as a lack of or low uptake of recommended pruning. In contrast, it highlights that the movement of recommended pruning and the sequential practice at different sites constrains the affordances available at the bottom end of the agriculture research value chain.

Unpacking in the extension site hinders the affordances of pruning to be made relevant and included into farmers' repertoires. Ultimately, this results in a practice with different and fewer affordances, while, as Glover et al. (2017) indicate, for a technology to make sense on the ground, it must create space for its affordances to be unpacked in new contexts. The reduced affordances are not necessarily a purposeful act of extensionists to alter established pruning and tree management practices of cocoa farmers but stem from how the agricultural research value chain is structured. Our analysis understands the low uptake of pruning as emanating from misfits as the pruning practices moves from research to extension and farming.

Therefore, we reframe the adoption problem as a matter of fit, which is conditioned by the institutional infrastructure shaping the travel that connects the enactment of pruning, as a GAP, at different sites. Looking into the conventions associated with the different sites helps to explain the persistence of misfit. For understanding the adoption problem, this shifts attention to values, visions and norms (Wilkinson 1997), as well as guides for actions and collective systems that legitimise actions (Ponte 2016) that constrain the flexibility 
required for fitting. Below, we discuss how these are evident in the conventions that guide and legitimise (1) how research is translated into manuals, (2) how information in manuals is reproduced in extension activities as fixed recommendations, and (3) how these recommendations are reinforced by sustainability-oriented certification programmes central to the governance of commodity chains.

First, translating research into manuals is a process of inscription that operates within the value of universal applicability of scientific knowledge. Thus, providing knowledge and practices of pruning in manuals, for instance, focuses on giving standard recommendations of the practice. The research site provides pruning illustrations from different contexts in manuals, which also orients knowledge exchange towards one type of pruning. Details on diverse types of pruning, its specificities, situatedness and diagnostic capacities fade in manuals. While standardising GAPs is a necessary level of inscription for making the package mobile, the fading of diversity, specificities, situatedness and diagnostic capacities in this process of inscription reduces the affordances of the package and the flexibility needed for fit.

Second, in extension delivery activities, the extension site operates within a shared interpretation (Diaz-Bone 2016) of manuals as sourcebooks. The site reproduces standardised recommendations in manuals, which reinforce a package with reduced affordances. Within this norm of relying on manuals, the site interprets 'recommended pruning' as the kind illustrated in manuals and equates these illustrations with 'good pruning'. Also, operating with a collective aim to increase adoption of GAPs among farmers, the site mobilises collective intentions and systems to legitimise (Ponte 2016) efforts towards increasing adoption of this recommended pruning. This manifests in the dovetailing of recommended pruning in sustainability programmes, certification schemes and related interventions with strong focus on adoption as well as using labour groups to deliver recommended pruning to farmers.

Third, the continuity of imposing recommended pruning dovetails with certification schemes and associated modes of training and service delivery. This reinforces misfit at the site of extension delivery, or deliberately organised encounters through which farmers come into contact with new packages (Glover et al. 2019). Activities, such as training sessions, demonstrations, coaching and gang pruning constitute another level of inscription guided by values of inspections and audits. These activities are complemented by disciplining actions imposed by incentives, punishments and managerial supervision (Glover et al. 2017) that reinforce the transfer of standard recommendations. The disciplining actions include: incentives embedded in persuading farmers to accept recommended pruning as part of bigger interventions comprising pesticide spraying and manual pollination, punishments evident in fear of failing certification audits for refusing recommended pruning, and managerial supervision imposed by the work of supervisors and superiors who inspect the work of gang pruners.

These disciplining actions, which are integrated in sustainability and certification programmes, reinforce prescriptive pruning with reduced affordances and constrain the flexibility necessary for fitting. Unpacking the affordances of pruning and enabling fitting requires the travelling package and the interaction interfaces to foster flexibility and room for manoeuvre (Vellema et al. 2020) and encourage reflexivity and expertise for diagnosing situated actions (Orlikowski 2002). However, the trajectories through which GAPs travel from the research to farming site and the interfaces of interactions leave little room for flexibility and reflexivity to foster fitting capacities.

Enabling fit requires presenting the package as malleable and involves farmers in diagnostic and evaluative processes unpacking the affordances and making them useful to their specific circumstances (Glover et al. 2017). However, the conventions at different sites constrain agricultural research value chains' capacity to enable fit and maximise package affordances. At the extension site, for instance, effective use of interactive extension approaches for situated diagnosis are considered resource-intensive and are rarely used (Muilerman and David 2011). Heuristics to help farmers make local adaptations are often lacking (Glover 2014). The conventions associated with manuals and recommended practices sustain the misfit. Misfit persists and is engendered by conventions directing collective systems that legitimise standardised recommendations of what is a rich and sophisticated practice. The conventions reinforce standard recommendations through standard-setting and certification schemes associated with sustainability endeavours in cocoa. This contributes to understanding the low uptake of recommended pruning among farmers.

\section{Conclusion}

In this paper, we analysed the low uptake of GAPs, specifically pruning, by examining what enables pruning to be and constrains it from being made relevant to and translated into farmers repertoires. We used the concepts of affordances and inscription to provide an account of the vertically coordinated travel of pruning from the site of research through extension to farming. We show that the non-adoption of pruning in Ghana's cocoa sector can be understood as misfit between the characteristics of pruning emerging in the enactment of the practices at different sites in the agricultural research value chain. Our paper moves the problem from farmers as non-adopters to the nature of inscription processes necessary for making pruning and other GAPs fit while being made mobile. With this view, we conclude 
that the uptake of GAPs is dependent on enabling fit in both their social and material elements. Examining the travel of pruning and anchoring this in the concept of fit shifts the research perspective to conventions. These conventions are strong and reproduce pathways that constrain the package of pruning to be made relevant to and translated into farmers repertoires. There is, therefore, a need to move beyond conceiving the low uptake of GAPs, such as pruning, as an adoption challenge that requires increased extension activities with standardised and de-contextualised recommendations. Our analysis creates space to think in terms of alternative pathways that foster flexibility. We suggest rethinking extension services embedded in global commodity chains, certification schemes and associated interventions to evade the adoption tragedy of forcing standardised good agricultural practices into situated action. This may translate into an institutional architecture with conventions that nourish fit and connect diagnostic capacities at different sites of the agricultural research value chain.

Acknowledgements This study was conducted under the project "Cocoa Crop Improvement, Farms and Market", funded by WOTRO Science for Development, the Dutch Research Council (NWO) (Project no. W 08.250.305).

Open Access This article is licensed under a Creative Commons Attribution 4.0 International License, which permits use, sharing, adaptation, distribution and reproduction in any medium or format, as long as you give appropriate credit to the original author(s) and the source, provide a link to the Creative Commons licence, and indicate if changes were made. The images or other third party material in this article are included in the article's Creative Commons licence, unless indicated otherwise in a credit line to the material. If material is not included in the article's Creative Commons licence and your intended use is not permitted by statutory regulation or exceeds the permitted use, you will need to obtain permission directly from the copyright holder. To view a copy of this licence, visit http://creativecommons.org/licenses/by/4.0/.

\section{References}

Akrich, M. 1992. The de-scription of technical objects. In Shaping technology/building society: Studies in sociotechnical change, ed. W. Bijker and J. Law, 205-224. Cambridge: MIT Press.

Alexander, K.S., G. Greenhalgh, M. Moglia, M. Thephavanh, P. Sinavong, S. Larson, T. Jovanovic, and P. Case. 2020. What is technology adoption? Exploring the agricultural research value chain for smallholder farmers in Lao PDR. Agriculture and Human Values 37: 17-32. https://doi.org/10.1007/s10460-019-09957-8.

Ansari, S.M., P.C. Fiss, and E.J. Zajac. 2010. Made to fit: How practices vary as they diffuse. Academy of Management Review 35 (1): 67-92.

Asare, R., V. Afari-Sefa, S. Muilerman, and G.J. Anim-Kwapong. 2018. Good agronomic practices in cocoa cultivation: Rehabilitating cocoa farms. In Achieving sustainable cultivation of cocoa, ed. P. Umaharan, 111-128. Cambridge: Burleigh Dodds.
Bromley, P., H. Hwang, and W.W. Powell. 2012. Decoupling revisited: Common pressures, divergent strategies in the US nonprofit sector. Management 15 (5): 469-501.

Coffey, A., and P. Atkinson. 1996. Making sense of qualitative data; complementary research strategies. London: Sage.

Cook, B.R., P. Satizábal, and J. Curnow. 2021. Humanising agricultural extension: A review. World Development. https://doi.org/10. 1016/j.worlddev.2020.105337.

Cox, M. 2012. Diagnosing institutional fit: A formal perspective. Ecology and Society 17 (4): 54. https://doi.org/10.5751/ ES-05173-170454.

David, S. 2011. Manual 2: Integrated crop and pest management for mature cocoa farms. In Good agricultural practices for sustainable cocoa production: A guide for farmer training, ed. R. Asare and S. David. Accra: Sustainable Tree Crops Program, International Institute of Tropical Agriculture.

Denkyirah, E.K., E.D. Okoffo, D.T. Adu, A. Aziz, A. Ofori, and E.K. Denkyira. 2016. Modelling Ghanaian cocoa farmers' decision to use pesticide and frequency of application: The case of Brong Ahafo region. Springerplus 5 (1): 1113-1113. https://doi.org/ 10.1186/s40064-016-2779-z.

Diaz-Bone, R. 2016. Convention theory and neoliberalism. Journal of Cultural Economy 9 (2): 214-220.

Dohmen, M.M., M. Noponen, R. Enomoto, C. Mensah, and S. Muilerman. 2018. Climate-smart agriculture in cocoa; A training manual for field officers. Accra: World Cocoa Foundation and Rainforest Alliance.

Dormon, E., C. Leeuwis, F.Y. Fiadjoe, O. Sakyi-Dawson, and A. van Huis. 2007. Creating space for innovation: The case of cocoa production in Suhum-Kraboa-Coalter District of Ghana. International Journal of Agricultural Sustainability 5 (2 \& 3): 232-246.

Elfving, D.C. 1990. Growth and productivity of 'Empire' apple trees following a single heading-back pruning treatment. HortScience 25 (8): 908-910.

Elliott, J. 2005. Using narrative in social research. London: Sage.

Fenger, N.A., S.A. Bosselmann, R. Asare, and A. de Neergaard. 2017. The impact of certification on the natural and financial capitals of Ghanaian cocoa farmers. Agroecology and Sustainable Food Systems 41 (2): 143-166.

Geurts, B. 2018. Conventions and common grounds. Mind and Language 33 (2): 115-129.

Glover, D. 2014. Of yield gaps and yield ceilings: Making plants grow in particular places. Geoforum 53: 184-194.

Glover, D., J. Sumberg, G. Ton, J. Andersson, and L. Badstue. 2019. Rethinking technological change in smallholder agriculture. Outlook on Agriculture 48 (3): 169-180.

Glover, D., J.P. Venot, and H. Maat. 2017. On the movement of agricultural technologies: Packaging, unpacking and situated reconfiguration. In Agronomy for development: The politics of knowledge in agricultural research, ed. James Sumberg, 14-30. Oxon: Routledge.

Govindaraj, K., and P. Jancirani. 2017. Effect of pruning on cocoa (Theobroma Cacao L) on morphological, flowering and yield and quality of cocoa beans. International Journal of Agricultural Science and Research 7 (6): 113-118.

Huett, D.O. 2004. Macadamia physiology review: A canopy light response study and literature review. Australian Journal of Agricultural Research 55: 609-624.

Jha, S., H. Kaechele, M. Lana, T.S. Amjath-Babu, and S. Sieber. 2020. Exploring farmers' perceptions of agricultural technologies: A case study from Tanzania. Sustainability 12: 998. https://doi.org/ 10.3390/su12030998.

Jin, J., X. Wan, R. He, F. Kuang, and J. Ning. 2020. Farmers' risk aversion, loss aversion and climate change adaptation strategies in 
Wushen Banner, China. Journal of Environmental Planning and Management 63 (14): 2593-2606.

Kumar, R. 2014. Research methodology: A step-by-step guide to beginners, 4th ed. London: Sage.

Laosutsan, P., G.P. Shivakoti, and P. Soni. 2019. Factors influencing the adoption of good agricultural practices and export decision of Thailand's vegetable farmers. International Journal of the Commons 13 (2): 867-880.

Latour, B. 1991. Technology is society made durable. In A sociology of monsters: Essays on power, technology and domination, ed. L. John, 103-131. London: Routledge.

Latour, B. 1992. Where are the missing masses? The sociology of a few mundane artifacts. In Shaping technology/building society: Studies in sociotechnical change, ed. W. Bijker and J. Law, 225-258. Cambridge: MIT Press.

Latour, B. 1999. The Pandora's hope: Essays on the realities of science studies. Cambridge: Harvard University Press.

McDonough, C., I.K. Nuberg, and W.S. Pitchford. 2015. Barriers to participatory extension in Egypt: Agricultural workers' perspectives. The Journal of Agricultural Education and Extension 21 (2): 159-176.

Meijer, S.S., D. Catacutan, O.C. Ajayi, G.W. Sileshi, and M. Nieuwenhui. 2015. The role of knowledge, attitudes and perceptions in the uptake of agricultural and agroforestry innovations among smallholder farmers in sub-Saharan Africa. International Journal of Agricultural Sustainability 13 (1): 40-54.

Muilerman, S., and S. David. 2011. Costs associated with farmer field schools and video viewing clubs on cocoa integrated crop and pest management: the experience of STCP. Impact brief, Sustainable Tree Crop Programme. Issue no. 08 March 2011. IITA.

Nadler, D.A., and M.L. Tushman. 1980. A model for diagnosing organizational behavior. Organizational Dynamics 9 (2): 35-51.

Nmadu, J.N., H. Sallawu, and B.V. Omojeso. 2015. Socio-economic factors affecting adoption of innovations by cocoa farmers in Ondo State, Nigeria. European Journal of Business, Economics and Accountancy 3 (2): 58-66.

Okoffo, E.D., M. Mensah, and B.Y. Fosu-Mensah. 2016. Pesticides exposure and the use of personal protective equipment by cocoa farmers in Ghana. Environmental Systems Research 5 (1): 1-15.

Opoku-Ameyaw, K., F. Baah, E. Gyedu-Akoto, V. Anchirinah, H.K. Dzahini-Obiatey, R.A. Cudjoe, S. Aquaye, and S.Y. Opoku. 2010. Cocoa manual: A source book for sustainable cocoa production. Ghana: Cocoa Research Institute of Ghana.

Orlikowski, W.J. 2002. Knowing in practice: Enacting a collective capability in distributed organizing. Organization Science 13 (3): 249-273.

Ponte, S. 2016. Convention theory in the Anglophone agro-food literature: Past, present and future. Journal of Rural Studies 44: 12-23.

Ponte, S., and P. Gibbon. 2005. Quality standards, conventions and the governance of global value chains. Economy and Society 34 (1): $1-31$.

Schouten, G., S. Vellema, and J. van Wijk. 2016. Diffusion of global sustainability standards: The institutional fit of the ASC-Shrimp standard in Indonesia. Revista De Administração De Empresas 56 (4): 411-423.

Smith, L.D., L.A. Best, D.A. Stubbs, J. Johnston, and A.B. Archibald. 2000. Scientific graphs and the hierarchy of the sciences: A Latourian survey of inscription practices. Social Studies of Science 30 (1): 73-94

Uda, S.K., G. Schouten, and L. Hein. 2018. The institutional fit of peatland governance in Indonesia. Land Use Policy 99: 103300. https://doi.org/10.1016/j.landusepol.2018.03.031.
Vellema, S., F. Obeng Adomaa, and M. Schoonhoven-Speijer. 2021. Making knowledge work in practice: An integrative methodology for researching performance in global commodity chains and local food markets. In The politics of knowledge in inclusive development and innovation, ed. D. Ludwig, B. Boogaard, P. Macnaghten, and C. Leeuwis, 256-268. Oxon: Routledge.

Vellema, S., G. Schouten, and R. van Tulder. 2020. Partnering capacities for inclusive development in food provisioning. Development Policy Review 38: 710-727. https://doi.org/10.1111/dpr.12466.

Vos, J.G.M., B.J. Ritchie, and J. Flood, eds. 2003. Discovery learning about cocoa; an inspirational guide for training facilitators. Surrey: CABI Bioscience.

Wilkinson, J. 1997. A new paradigm for economic analysis? Economy and Society 26 (3): 335-339.

Publisher's Note Springer Nature remains neutral with regard to jurisdictional claims in published maps and institutional affiliations.

Faustina Obeng Adomaa is a $\mathrm{PhD}$ candidate at the Knowledge, Technology and Innovation group, Wageningen University. Her research is at the intersection of institutional analysis and inclusive development in commodity chains in West Africa. She is interested in understanding factors that enable or constrain commodity chains and associated service delivery models to be inclusive and to fit the diverse realities of chain actors.

Sietze Vellema is Associate Professor at the Knowledge, Technology and Innovation group, Wageningen University. He is also senior researcher at the Partnerships Resource Centre, Rotterdam School of Management and at the Centre for Frugal Innovation in Africa, Erasmus University Rotterdam. Sietze is involved in integrative studies that aim to understand why and how different actors collaborate in solving organizational, managerial, and technical problems related to inclusive development and sustainable food provision, based on (action) research in Africa and Southeast Asia.

Maja Slingerland is Associate Professor at the Plant Production Systems group, Wageningen University. She has over 30 years experiences in research aimed at increasing social-economic and environmental sustainability of farming systems and supply chains in different countries. She leads research on perennial crops, such as oil palm and cocoa. Currently she leads an interdisciplinary multi-stakeholder project on cocoa in Ghana and Ivory Coast with several PhD researchers, funded by the Dutch Science Foundation.

Richard Asare works with the International Institute of Tropical Agriculture (IITA) as the Country Representative for Ghana, and Coordinator for Cocoa Research for Development. He also serves as the coordinator for the global CocoaSoils Programme and the CGIAR's program on Climate Change, Agriculture and Food Security that looks at Mainstreaming climate smart agriculture in cocoa systems in Ghana. He also worked as the Focal Point, coordinating scientific activities under the CGIAR Research Program on Integrated Systems Research for the Humid Tropics (Humidtropics) in West, East and Central Africa. 